\title{
Strongyloides stercoralis: current perspectives
}

This article was published in the following Dove Press journal:

Reports in Parasitology

23 May 2016

Number of times this article has been viewed

\section{Ravi Varatharajalu' \\ Kakuturu V Rao ${ }^{2}$}

'The Department of Biochemistry and Molecular Medicine, The George Washington University, VA Medical Center, Washington, DC, ${ }^{2}$ American Molecular Laboratories, Vernon Hills, IL, USA
Correspondence: Ravi Varatharajalu The Department of Biochemistry and Molecular Medicine, The George Washington University,VA Medical Center, 50 Irving Street, Northwest, Washington, DC 20422, USA

Tel +l 2027458000 ext 57643 Fax +I 2024622006

Email ravi.varatharajalu@va.gov/ rvaratha@gwu.edu
Abstract: Strongyloides stercoralis is an intestinal nematode parasite with a global distribution. Most infected individuals have few or no symptoms. Strongyloidiasis is of primary medical importance, and fatal disease can occur in infected people who become immunosuppressed/ immunocompromised through the administration of steroids or because of coinfection with human T-lymphotropic virus I. Often, misdiagnoses of strongyloidiasis in patients leads to expensive, nonspecific, invasive diagnostic techniques, including endoscopy, barium swallow, cancer biopsies, chest X-rays, and computerized tomography (CT) scans. Delayed treatment for strongyloidiasis brings in medical complications, such as vomiting, diarrhea, anemia, weight loss, pulmonary abnormalities, and septicemia. Chronic infection is difficult to diagnose by standard stool examination; hence, a reliable recombinant antigen-based serodiagnosis is important. Though albendazole and thiabendazole reduce the burden of the disease, they are not effective in an immunocompromised host. Ivermectin has the advantage of eradicating the disease, even in an immunocompromised host, with fewer side effects compared to albendazole. However, drug treatment is a temporary solution since reinfection can often occur. Thus, developing effective vaccine candidate antigens is imperative to stop the disease.

Keywords: strongyloidiasis, hyperautoinfection, albendazole, thiabendazole septicemia, immunocompromised host, HTLV-1, ivermectin, gastrointestinal

\section{Introduction}

Strongyloidiasis, a human intestinal parasitic infection, is caused by Strongyloides stercoralis and S. fuelleborni. S. stercoralis accounts for $>90 \%$ of infections and is endemic in Africa, South America, and Southeast Asia. S. fuelleborni is primarily found in nonhuman primates, but human infections have also been reported from Central Africa $^{1}$ and Papua New Guinae. ${ }^{2}$ Strongyloidiasis infection is endemic in areas with poor hygiene, unorganized and ineffective health care facilities, and unequal socioeconomic conditions. Other major causes for the spread of infection are high humidity, open defecation, walking barefoot, or playing in such an environment. However, the occurrences of $S$. stercoralis were reported even from temperate and subtropical regions, such as southern part of USA, Europe, ${ }^{1,3}$ and Okinawa in Japan. ${ }^{1}$ Several case reports from developed countries suggest that strongyloidiasis is an emerging disease in even nonendemic regions due to $S$. stercoralis-infected people emigrating from endemic to developed countries and travelers and veterans returning after serving in the endemic countries. 


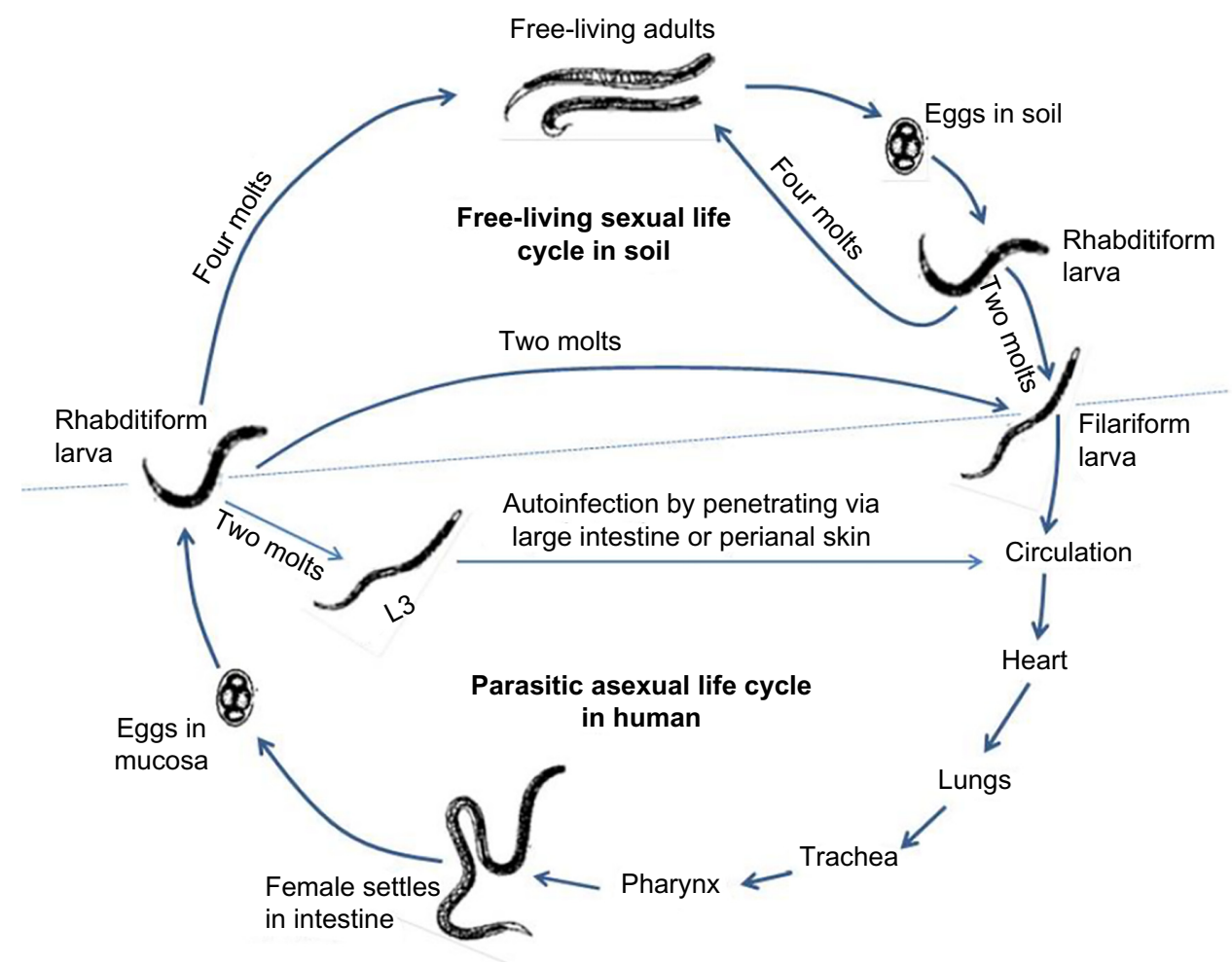

Figure I The Strongyloides life cycle is complex with its alternation between free-living and parasitic cycles.

Notes: Free-living cycle: the rhabditiform larvae passed in the stool can become either infective filariform larvae (direct development) or free-living adult males and females that mate and produce eggs from which rhabditiform larvae hatch and eventually become infective filariform larvae. The filariform larvae penetrate the human host skin to initiate the parasitic cycle. Parasitic cycle: filariform larvae in contaminated soil penetrate the human skin and by various, often random, routes migrate into the small intestine. Historically, it was believed that the L3 larvae migrate via the bloodstream to the lungs, trachea, and pharynx where they are eventually coughed up and swallowed. However, there is also evidence that L3 larvae can migrate directly to the intestine via connective tissues. In the small intestine, they molt twice and become adult female worms. The females live threaded in the epithelium of the small intestine and parthenogenetically produce eggs, which yield rhabditiform larvae. The rhabditiform larvae can either be passed in the stool for free-living cycle or develop to filariform larvae within the large intestine and can cause autoinfection.

Abbreviation: L3, third larval stage.

\section{Life cycle}

Figure 1 shows two life cycles of $S$. stercoralis depending on the environment: a free-living, nonparasitic sexual life cycle and parasitic asexual life cycle. The free-living male and female worms mate and the female releases the rhabditiform (first-stage larva [L1]) larvae in the moist soil. These rhabditiform larvae molt four times to become young male and female worms for the next cycle of free-living sexual reproduction, whereas some rhabditiform larvae molt twice to become infective third-stage larvae (L3i) (filariform), which can enter the human host to lead a parasitic asexual life cycle. The infected filariform larvae pass through the blood, transmigrate into the alveoli of lungs, trachea, pharynx, esophagus, and stomach, and finally reach into the submucosal layer of duodenum where they molt twice to become adult female worms. ${ }^{4-6}$ Female adult worms that burrow into the submucosa of the small bowel asexually produce eggs. The eggs hatch into rhabditiform larvae (L1), which are released into the lumen of the intestine and are excreted in stool. However, in some cases, delayed defecation or constipation can induce the L1 larvae to molt to L2 and then to infective filariform larvae (L3). The infective filariform larvae gain access to the bloodstream by penetrating the colonic or rectal mucosa or perianal region. This particular process of infection is called autoinfection and is responsible for the perpetuation of the parasite even after a long period after original infection. However, in immunosuppressed individuals, this process of autoinfection is enhanced multiple times that leads to larval dissemination of severe strongyloidiasis. Therefore, early diagnosis helps treatment with antihelminthic drugs for this potentially fatal but eminently curable disease.

\section{Epidemiology and clinical symptoms}

Figure 2 shows the worldwide distribution of strongyloidiasis. It is commonly distributed in tropical and subtropical countries, highly endemic in Southeast Asia, Africa, South America, and has a frequent occurrence even in Europe and USA. ${ }^{7}$ Based on fecal tests, clinical presentations, and duodenal lavage biopsy tests, it is estimated that globally 30-100 million people are infected. However, the estimated 


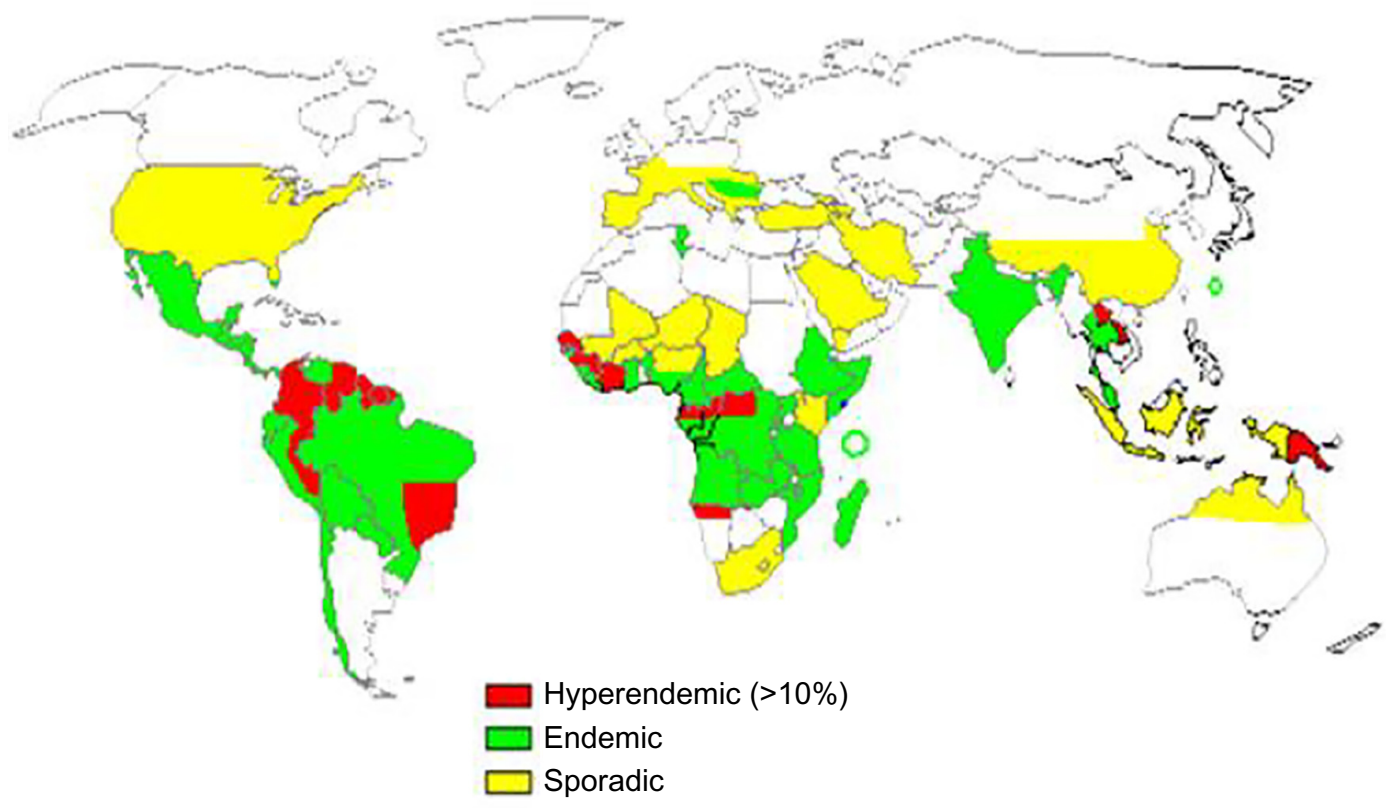

Figure 2 Global distribution of Strongyloides stercoralis.

Notes: Sporadic reports of prevalence are shown in yellow. Endemic countries are shown in green. Hyperendemic regions are shown in red. Reused with permission from the World Gastroenterology Organisation from WGO Practice Guideline: Management of Strongyloidiasis, October 2004.

global burden of strongyloidiasis is arbitrary due to the lack of accurate diagnostic methods. Insensitive and laborious fecal tests underestimate the disease prevalence, whereas a sensitive enzyme-linked immunosorbent assay (ELISA) method using crude $S$. stercoralis somatic antigen overestimates the disease prevalence due to cross-reactivity with other nematode parasite infections in S. stercoralis-endemic areas. Accurate statistics of global distribution of the parasite remains uncertain until a gold standard diagnostic method is available.

In the immunocompetent human host, mild persistent internal autoinfections can occur for many years or lifelong without eliciting obvious clinical symptoms. More than $50 \%$ of patients infected with the parasite report no symptoms. ${ }^{89}$ Minor clinical manifestation due to acute infection is rarely diagnosed. Acute infection may result in chronic disease with various clinical symptoms mostly associated with gastrointestinal tract and in some cases include pulmonary manifestation. Immune suppression due to steroid therapies in tissue transplantation cases or cancer therapies leads to chronic hyperautoinfection and disseminated strongyloidiasis. Disseminated autoinfection transports intestinal fauna into the bloodstream along with the penetrating parasites across the intestinal mucosal layer that could cause septic shock.

S. stercoralis infection in nonendemic area goes unnoticed or often misdiagnosed since this infection is unexpected by the physicians. Without knowing the underlying strongyloidiasis infection, patients often undergo various complicated clinical procedures and nonspecific chemotherapies. ${ }^{8,10}$

\section{Strongyloidiasis in children}

Children growing in poor hygienic and unsanitary conditions are at high risk for $S$. stercoralis infection. However, $>50 \%$ of infected children report no symptoms. Severe cases of S. stercoralis infection in children present clinical ailments, such as malnourishment due to malabsorption, intermittent diarrhea, vomiting, poor immunity, fragile body structure, fatigue, growth failure and weight loss, abdominal distention and tenderness, abdominal bloating and discomfort, upper abdominal pain, eosinophilia, steatorrhea, and protein loss. ${ }^{11}$ Paralytic ileus may cause frequent constipation due to acute strongyloidiasis in children. A more recent study in Darwin, Australia, found that children with $S$. stercoralis were more likely to be hypokalemic and wasted than children with diarrhea caused by other pathogens. ${ }^{12}$ Gastrointestinal symptoms were present in $72 \%$ of these cases and half of the children were younger than 5 years..$^{13}$ Refugees' children ( $\mathrm{n}=163$ patients) were admitted between 2008 and 2009 to Pediatric Internal Health Clinic, State University of New York Hospital, Stony Brook, USA. The median patient age of children was 8 years with a range of 8 months to 18 years who arrived from Southeast Asia (59\%) or Africa (27\%) and Middle East (14\%). Overall, $24 \%$ of these patients were seropositive for Strongyloides, $8 \%$ 
were positive for schistosomes, and 19\% had absolute eosinophilic count $>400 / \mu \mathrm{L} .{ }^{14}$ S. stercoralis infections were prevalent in $27 \%$ of children in Doomadgee and Gununa, Australia, after thiabendazole treatment fell $<7 \%$. ${ }^{15}$

\section{Pulmonary strongyloidiasis}

S. stercoralis infections are often mild and associated with few or no symptoms. However, during the lung migratory phase, filariform larvae may induce inflammatory reactions, such as pneumonitis, bronchopneumonia, and pulmonary hemorrhage, including fever, ${ }^{16}$ productive cough, wheezes, dyspnea hemoptysis, and bronchospasm. ${ }^{17-19}$ Pulmonary symptoms, including dyspnea, cough, and sputum discharge, were recorded in $15.7 \%$ of $S$. stercoralis-infected cases. ${ }^{20}$ People with chronic bronchitis, emphysema, pulmonary fibrosis, asthma, ${ }^{21,22}$ and immunosuppression have a higher risk of pulmonary strongyloidiasis (PS). ${ }^{23-25}$ Chronic pulmonary abnormalities such as mucous plugging of bronchi, bullae, pulmonary fibrosis, and any preexisting pulmonary-associated infection may delay the transmigration of filariform larvae through alveoli and trachea, which allows infective larvae to mature well in the lung itself. ${ }^{18}$ A matured adult female lays embryonated eggs that hatch into rhabditiform larvae. The repetition of the entire life cycle within the lungs can then lead to severe PS. Widespread dissemination of $S$. stercoralis throughout the thorax may occur, resulting in pulmonary hemorrhage with hemoptysis, pleuritis with hemorrhagic pleural effusion, severe bronchopneumonia, ${ }^{21,26}$ hoarseness, ${ }^{27}$ chest pain, ${ }^{28}$ dyspnea, ${ }^{29}$ and respiratory failure. ${ }^{25}$ Clinical diagnosis of PS is often delayed because of nonspecificity of signs and symptoms. Treatment courses are often misdirected toward asthma, allergy, and chest X-ray and in some cases diagnosed as lung cancer. Inappropriate therapy with a corticosteroid may then lead to worsening of the patient's condition. It is necessary to educate physicians to investigate strongyloidiasis as a probable cause based on the endemic region or travel history of patients with pulmonary and gastrointestinal symptoms and with peripheral blood eosinophilia. If strongyloidiasis is suspected, examination of sputum, stool, and duodenal aspirates or parasite-specific ELISA ${ }^{30}$ is warranted for diagnosing strongyloidiasis in patients with steroid-dependent unexplained lung disease or lung shadows of miliary nodulation or diffused interstitial reticulation in chest X-rays or computerized tomography (CT) scans. ${ }^{18,24,26,31}$

\section{Strongyloidiasis in HIVIAIDS}

Patients with HIV infection or AIDS are susceptible to strongyloidiasis coinfection since humoral and CD4- mediated immunities are severely compromised. Patients with advanced HIV-positive and S. stercoralis coinfection failed to respond to the standard course of thiabendazole or ivermectin treatment and died due to disseminated infection. ${ }^{32,33}$ HIV and S. stercoralis coinfection were strongly associated with other bacterial infections, especially those transferred from intestines, and caused Escherichia coli meningitis. However, the incidence of strongyloidiasis is low in the AIDS pandemic/strongyloidiasis-endemic areas, and it was shown that the frequency of strongyloidiasis is not significant between HIV-infected and normal population. In Lusaka, Zambia, only $6 \%$ of patients with HIV infection $(n=63)$ were $S$. stercoralis positive by stool examination. ${ }^{34}$ Dually infected patients show almost similar clinical complications to those of $S$. stercoralis-infected immunocompetent patients. Recent evidence suggested that even with severe depletion of CD4 cells, patients with AIDS control dissemination of $S$. stercoralis. Since HIV infection predominantly impairs Th1 response and not $\mathrm{Th} 2$, the unaffected $\mathrm{Th} 2$ response effectively controls the parasite by eliciting parasite-specific IgE antibody production and eosinophil response. ${ }^{35}$

\section{Strongyloidiasis and human T-lymphotropic virus}

Human T-lymphotropic virus I (HTLV-1) is endemic in Africa, Japan, the Caribbean, and South America. HTLV-1 is a retrovirus that primarily affects CD4 T-lymphocytes, alters gene expression, and increases T-cell proliferation. Most HTLV infections have long latent period and are asymptomatic. HTLV-1 is primarily associated with two diseases, adult T-cell leukemia (ATL) and HTLV-1-associated myelopathy/tropical spastic paraparesis. The prevalence rate of Strongyloides infection was significantly higher in HTLV-1 carriers (31.6\%) than in those without HTLV-1 (6.3\%) infection in Okinawa, Japan. ${ }^{36,37}$ The high prevalence of strongyloidiasis infection in HTLV-1-infected individuals is attributed to immunosuppression. Approximately 39\% of patients with S. stercoralis infection stimulated the oligoclonal expansion of HTLV1-infected lymphocytes in HTLV-1 asymptomatic carriers, suggesting the shortened period of latency in ATL patients with strongyloidiasis. ${ }^{38}$ S. stercoralis-induced HTLV-specific oligoclonal expansion is partly mediated by the IL-2/IL-2R upregulation caused by the viral transactivator Tax protein. Thus, strongyloidiasis is frequently associated with lymphoid malignancies, including ATL. ${ }^{39}$ Significantly elevated provirus load positively correlated with the population of $\mathrm{CD} 4^{+} 25^{+}$ T-cells in dually infected carriers. ${ }^{38}$ In addition, S. stercoralis antigen significantly induced IL-2 production by peripheral 
blood mononuclear cells (PBMC) and activated IL-2 promoter that helps Tax-immortalized T-cells in vitro. ${ }^{39}$

High mortality rate of $\sim 36 \%$ was observed in hyperautoinfective strongyloidiasis in HTLV-1 carriers. ${ }^{40}$ Furthermore, there is a decrease in the efficacy of treatment in patients coinfected with HTLV-1 and S. stercoralis. ${ }^{5}$ The cure rate of $S$. stercoralis was lower in HTLV-I carriers ${ }^{41,42}$ due to decreased $\operatorname{IgE}(P<0.05)$ and increased IgG4 $(P<0.05)$ observed in the noncured group, especially in HTLV-I carriers. ${ }^{43}$ It has been reported that despite several courses of thiabendazole therapy, $S$. stercoralis reappeared in stool samples, resulting in the recommendation of a double dose of ivermectin $(200 \mu \mathrm{g} / \mathrm{kg})$ in patients positive for anti-HTLV-1 antibody. ${ }^{44}$ Hyperinfective strongyloidiasis may also be a clinical marker of HTLV-1 infection in areas where both entities are endemic or in immigrants from such areas (Figure 2). Strongyloides hyperinfection syndrome in HTLV-1 carriers was due to selective impairment of parasite-specific IgG as well as IgE antibody production. ${ }^{36,45} \mathrm{HTLV}-1$ coinfection with S. stercoralis decreased the production of IL-4, IL-5, IL-13, and $\operatorname{IgE}$ antibodies. These cytokines are very important for humoral as well as cellular immunities against helminths. Eosinophils and $\operatorname{IgE}$ antibody levels were low even after treatment with ivermectin in patients with $S$. stercoralis and HTLV coinfections, ${ }^{37}$ suggesting that HTLV-1 dysregulated parasite-specific immunity. It was reported that HTLV-1 and $S$. stercoralis coinfection increased regulatory T-cells $\left(\mathrm{CD} 4^{+} \mathrm{CD} 25^{+} \mathrm{FoxP}^{+}\right)$that downregulate parasite-specific IL-5 and eosinophil production, as a selective impairment of immunity against parasites. ${ }^{46,47}$

\section{Drug treatment}

The goal of drug treatment is to eliminate both the adult worms and larvae in order to eradicate the infection, reduce the morbidity, and prevent complications. It is recommended to treat all the patients who harbor Strongyloides, even if they are asymptomatic, because of the risk of hyperinfection. Strongyloides hyperinfection syndrome, usually precipitated by immune suppression, should be considered in patients who reside in the endemic regions or traveled from endemic regions to other nonendemic countries. Attempts at the detection and eradication of this infection are recommended to prevent this potentially fatal complication. However, for infected pregnant patients, clinicians may prefer to defer treatment for strongyloidiasis until after the first trimester. Strongyloides species are the hardest worms to eradicate and to ensure this, posttherapy stool examinations are also recommended to verify Strongyloides eradication and to exclude other parasitic infections. Empirical corticosteroid administration for treating wheezing could be problematic, because it may cause life-threatening hyperinfection.

Benzimidazoles (thiabendazole, mebendazole, and albendazole) are anthelmintic agents that disrupt energy production in the parasites by inhibition of beta-tubulin polymerase, which causes disruption of cytoplasmic microtubule formation. Ivermectin inhibits neurotransmission in nematodes by stimulating the release of gammaaminobutyric acid-dependent neurotransmission. Ivermectin and thiabendazole have shown to be superior to albendazole, and ivermectin is becoming the drug of choice in many countries due to its more favorable side effects compared to benzimidazoles. A standard dose of $200 \mu \mathrm{g} / \mathrm{kg}$ ivermectin for 2 days is recommended. However, patients with hyperinfection and disseminated disease should be administered ivermectin daily until symptoms have resolved and larvae have not been detected for at least 2 weeks. A newer drug, tribendimidine, remains under investigation in the People's Republic of China and shows some promise in the treatment of strongyloidiasis. ${ }^{48}$

The efficacy and safety of thiabendazole and ivermectin were evaluated, with thiabendazole at $25 \mathrm{mg} / \mathrm{kg} / 12 \mathrm{~h}$ for 3 consecutive days and ivermectin at $200 \mu \mathrm{g} / \mathrm{kg}$ as single dose and another group with the same dose of ivermectin for 2 consecutive days. It was found that the criteria for cure were met with $78 \%$ treated with thiabendazole, $77 \%$ treated with ivermectin single dose, and 100\% treated with 2 days ivermectin regimen. These studies further suggested that ivermectin has fewer complaints than thiabendazole. ${ }^{49,50}$ In another study, comparing the efficacy of single-dose ivermectin $(200 \mu \mathrm{g} / \mathrm{kg})$ with 3 days of albendazole $(400 \mathrm{mg} / \mathrm{d})$ for the treatment of $S$. stercoralis in 301 children resulted in $83 \%$ and $45 \%$ efficacy, respectively. ${ }^{51}$ Another advantage of ivermectin is its effect in eliminating Ascaris lumbricoides, another common intestinal nematode parasite in children. ${ }^{51}$ In a case study, a 10-year-old boy receiving chemotherapy for T-cell lymphoblastic lymphoma became severely ill with disseminated strongyloidiasis. He responded to antibiotics and albendazole treatment but required ivermectin to eradicate the Strongyloides infection. ${ }^{52}$ S. stercoralis-infected children received prednisolone therapy, and concomitant thiabendazole treatment was ineffective in eliminating the parasite; all these patients died due to disseminated strongyloidiasis. ${ }^{53}$ Genetic predisposition plays an important role in treatment, as described by Satoh et al, who showed albendazole treatment failure due to a significantly elevated $S$. stercoralisspecific IgG4 in HLA-DRB1*0901 carriers. $^{54}$ 
Thiabendazole was successfully used in patients with HIV infection and most of them responded well. Before the start of chemotherapy for HIV, prescreening was needed for strongyloidiasis based on a report of dissemination of S. stercoralis as an immune restoration phenomenon in an HIV-1-infected man on antiretroviral therapy. ${ }^{55-57}$ Because of the risk of hyperinfection and/or disseminated disease in patients with AIDS, multidose courses of ivermectin $200 \mu \mathrm{g} / \mathrm{kg} / \mathrm{d}$ are warranted till the cure. ${ }^{57}$

\section{Diagnostic advances}

Direct microscopic observation of the parasite in thick wet smeared feces or Saline/Lugol's iodine staining method shows $\sim 30 \%$ sensitivity for $S$. stercoralis diagnosis. ${ }^{58}$ This poor sensitivity is due to low larval output in the case of mild infection of parasite and sporadic release of the larvae. Many techniques were periodically used to improve the sensitivity to detect Strongyloides larvae in stool samples. Various other standard methods that increased the sensitivity of diagnosis are larval concentration and culture methods, including Baermann, formalin-ethyl acetate sedimentation techniques, Harada-Mori, charcoal filter paper, and nutrient agar culture plate methods. The Baermann technique is laborious and unpleasant but increased the diagnostic sensitivity only by $7.4 \%$ compared to microscopic examination of direct thin smear. ${ }^{59}$ Although the agar plate method increased the sensitivity by an additional $6.4 \%$ over the Baermann method, this method needs $>48$ hours. Many investigators relied on the agar plate method since it is simpler than the Baermann method. ${ }^{59}$ However, Sato et al showed that $40 \%$ of samples consisted of false-negative (did not detect) larvae by agar culture plate techniques, concluding that sensitivity of this method is only $60 \% .{ }^{60}$ With these disadvantages and due to sporadic release of larvae, many investigators adopted to repeated sampling for increasing the diagnostic sensitivity. ${ }^{59}$

Molecular diagnostic methods for the detection of S. stercoralis-specific DNA in stool samples were attempted by a few investigators using polymerase chain reaction (PCR) amplification techniques. The sensitivity of a real-time PCR-based diagnostic method of another tropical parasite, Schistosoma mansoni, was at least 100 eggs per gram of feces and failed to detect $<100$ eggs per gram of feces.$^{61}$ Similar approach was adopted to detect $S$. stercoralis in human feces using real-time PCR with species-specific target genes, such as cytochrome $c$ oxidase, $18 \mathrm{~S}$ rRNA, and 5.8S rRNA. ${ }^{62-66}$ The real-time PCR was $100 \%$ specific but failed to enhance the sensitivity to detect strongyloidiasis compared to parasite concentration methods. ${ }^{67}$ The major disadvantage of DNAbased detection is that the amount of parasite-specific DNA in the feces is variable because of sporadic larval release, and in asymptomatic patients with very low levels of larval output, the test is unlikely to achieve a higher sensitivity unless repeated stool samples are tested. Moreover, this method is expensive and technically challenging for implementation in the Third-World countries.

To improve the sensitivity and specificity of $S$. stercoralis diagnosis, several investigators attempted to find a suitable protein candidate antigen(s) from the larval surface or the excretory secretory products ${ }^{68}$ and somatic antigens. Some of the promising candidate antigens were identified from somatic extracts at molecular weights of 28,31 , and $41 \mathrm{kDa} .{ }^{69}$ These antigens were recognized by antibodies in sera from $S$. stercoralis-infected individuals, but the specificity of these antigens is yet to be determined. ${ }^{70}$ S. stercoralis crude somatic antigen detected $87 \%-94 \%$ of parasite-specific antibodies in strongyloidiasis as reported by various investigators. ${ }^{30,71-74}$ However, the disadvantage of crude L3 somatic antigens is the presence of cross-reacting epitopes that are recognized by sera from other helminthic parasites: Onchocerca volvulus by $80 \%$, Wuchereria bancrofti by $70 \%,{ }^{29}$ and other parasitic infections, such as Ascariasis and Schistosomiasis. ${ }^{74,75}$

Recombinant antigens 5a and 12a identified from S. stercoralis L3 larvae were capable of detecting IgG antibodies in sera from $S$. stercoralis-infected humans and did not cross-react with sera from filarial parasites. ${ }^{76} \mathrm{~A}$ diagnostic ELISA developed to detect antibodies in S. stercoralisinfected humans using the recombinant NIE antigen showed $88 \%$ specificity and $95 \%$ sensitivity. ${ }^{30}$ The recombinant NIE antigen assay that was used to study the seroprevalence of strongyloidiasis in Sudanese refuges in USA showed that $33 \%$ were positive to $S$. stercoralis infection. ${ }^{77}$ This assay was also used to screen the refugees or immigrants to Canada from Asia, Africa, and South America and revealed a prevalence rate of $>30 \%$ of S. stercoralis infection in this population (Greenway, unpublished data, 2007). NIE ELISA ${ }^{30}$ and NIE luciferase immunoprecipitation system assays ${ }^{78}$ showed no cross-reactivity with serum samples from patients with filarial infection.

Eosinophilia is another prognostic marker commonly seen in Strongyloides-infected patients with intact immune systems, but it may be absent in immunosuppressed patients. ${ }^{79,80}$ Patients with hyperinfection who have peripheral eosinophilia appear to have a better prognosis than patients without peripheral eosinophilia. ${ }^{40}$ However, eosinophils are not specific to Strongyloides since any helminthic infection can 
elicit eosinophil response. A second episode of $S$. stercoralis infection is an important cause of severe pulmonary infection and obstruction and causes even death. ${ }^{81}$ Microscopic observation of unstained or Lugol- or Gram-stained sputum or lung lavage is a diagnostic method for PS. Symptoms of PS are wheezing and shortness of breath, similar to asthma symptoms, with elevated peripheral eosinophil count and parasite-specific IgE antibodies known as tropical pulmonary eosinophilia. ${ }^{47}$

Invasive diagnostic methods such as duodenal aspirate, biopsies, and endoscopy are insensitive in the early stage of diagnosis. Examination of single specimens of duodenal fluid under the microscope revealed to be more sensitive than wet mount analysis of stool samples for the detection of larvae. However, it was observed that this method is $24 \%$ false negative. ${ }^{82}$ Moreover, in some cases, histological observation of duodenal biopsy specimens may show the presence of $S$. stercoralis embedded in the mucosa. ${ }^{83,84}$

We conclude that the concentration methods of Strongyloides larvae, conventional crude somatic ELISA to detect parasite-specific antibodies, and PCR-based detections of parasite-specific ribosomal markers are plagued by poor specificity and sensitivity, higher cost, and labor-intensive methods. Commercial development and deployment of a simple, specific, and sensitive method using well-studied recombinant antigens is ideal for the detection of this parasitic infection and will be beneficial in eradicating this disease in combination with prompt drug treatment.

\section{Vaccine development}

Strongyloidiasis is a long-neglected parasitic disease, and research studies to develop a suitable vaccine are also scanty. Only few authors have reported the attempts of identifying and developing novel and potential vaccine candidate antigens in a mice model using deoxycholate-soluble affinitypurified L3 antigens of various molecular sizes of 80, 75, $61,57,43$, and $42 \mathrm{kDa}$. This antigen pool stimulated the proliferation and secretion of IL- 5 by splenocytes that were recovered from mice immunized with live L3. Vaccination of mice with these immunoaffinity-isolated antigens significantly increased protective immunity by killing $83 \%$ of challenged larvae. ${ }^{85}$ Recently, the same group reported yet another potential recombinant surface antigen known as SS-IR, a S. stercoralis surface-specific antigen, that decreased $80 \%$ of worm burden. ${ }^{86}$ In another study, intradermal vaccination of mice with $\mathrm{Na}^{+}-\mathrm{K}^{+}$ATPase DNA significantly reduced larval survival. ${ }^{87}$ Protective IgG from mice immunized with live L3 requires complement activation and neutrophils for the killing of L3 through an antibody-dependent cellular cytotoxicity mechanism. ${ }^{88}$ Abraham et al showed that immunization of BALB/c mice with 10,000 live L3 larvae eliminated $97 \%$ of the larvae either contained in diffusion chambers or free within the tissue of the mouse within 24 hours of postinfection. Sera from these immunized mice had elevated levels of IgG1, IgM, and IgA isotypes specific to the parasite; IgM was the only antibody isotype that recognizes surface antigens of L3. ${ }^{89}$ In another closely related Strongyloides ratti (Sr) species study, mice immunized with a native form of SrHsp60 or with complete Freund's adjuvant developed predominantly dysregulated Th1 response that allowed a higher larval output and was not protective. However, the same SrHsp60 precipitated with alum induced Th2 cell response that conferred partial protection against the challenge infections, suggesting the importance of adjuvants for vaccination studies. ${ }^{90}$ In another study, the same group reported that passive immunization of mice with monoclonal anti-srHSP60 IgM led to reduced numbers of migrating larvae in the lung and head, reduced parasitic adults in the small intestine, and reduced the larval output upon $S$. ratti challenge infection. ${ }^{91}$ Vlaminck et al reported the effect of adjuvant in inducing protective immunity, with deoxycholic acid-soluble antigen prepared from $S$. venezuelensis and used with saponin extract from Quillaja saponaria and with immunomodulatory substances. Phlebodium pseudoaureum hydroalcoholic extracts induced the highest level of protection in terms of fecal egg count reduction by $93 \%-99 \% .{ }^{92}$ Since, both $S$. ratti and $S$. venezuelensis are primarily rodent infections, vaccination studies using these parasites need further validation for human-specific $S$. stercoralis.

\section{Genomics of Strongyloides}

The genome of $S$. stercoralis is $\sim 43 \mathrm{Mbp}$, organized in six chromosomes in the female and five chromosomes in the male. The sex is determined by one pair of $\mathrm{X}(\mathrm{XX})$ in the female and a single $\mathrm{X}(\mathrm{XO})$ in the male. ${ }^{93}$ Because of the extra $\mathrm{X}$ chromosome, females are capable of reproducing parthenogenetically to both female and male offspring. It is estimated that the genome of $S$. stercoralis codes for 13,114 genes, which have significantly fewer and smaller introns compared to Caenorhabditis elegans and parasitic nematodes representing Clades I, III, and V. ${ }^{94,95}$

With the advent of DNA sequencing technology, the initial focus of genomic analysis was sequencing of expressed sequence tags (ESTs), or short DNA sequences of gene-coding regions reverse-transcribed from mRNA, to identify diagnostic and vaccine candidate genes. Ramachandran et al initially 
submitted S. stercoralis filariform and rhabditiform ESTs to the GenBank, most of which were immunoreactive with human sera. ${ }^{76}$ The program for nematode genome sequencing initiative included S. stercoralis and $S$. ratti (commonly found in rat host) EST sequencing. As of now, 10,908 ESTs grouped into 3,479 contigs were sequenced from $S$. stercoralis and 14,761 ESTs grouped into 4,152 clusters and 5,237 contigs were sequenced from $S$. ratti. ${ }^{96,97}$ Thus, a total of 25,669 EST sequences are available from the L1 and L3i larvae of S. stercoralis and five stages of $S$. ratti (http://nematode.net). Mitreva et al compared ESTs of L1 and L3i larvae of S. stercoralis with L3i-like dauer stage larvae of C. elegans. ${ }^{98}$ Comparison of S. stercoralis L1 and L3i-biased or -specific clusters with C. elegans nutrientrich or dauer-specific genes showed significant matches between $S$. stercoralis L1 and C. elegans nutrient-rich-specific transcripts only; thus, the conservation of transcriptional profiles of L3i of S. stercoralis and dauer larvae of C. elegans was not supported by this analysis. ${ }^{98}$ The cluster consensus sequences of $S$. ratti were used to assign each cluster to one of the three databases: 1) C. elegans and C. briggsae sequences, 2 ) other nematode sequences, and 3) nonnematode sequences. The authors found that $\sim 25 \%$ of clusters have no significant alignment and may therefore represent novel genes. ${ }^{96}$ This high level of nonalignment is a feature of nematode EST analyses, which probably reflects both the large evolutionary distance between taxa and the diversity of life histories. ${ }^{99}$ There was a specificity of substantial free-living and parasitic stages in the detected ESTs. ${ }^{100}$

The complete mitochondrial genome sequence of S. stercoralis is $13,758 \mathrm{bp}$ in size coding for 36 genes (coding for 12 proteins, $22 t R N A s$, and two $r R N A s$ ) and an AT-rich (control) region but lacks an atp 8 gene, similar to most nematodes examined to date. All genes are inferred to be transcribed in the clockwise direction. ${ }^{101}$

The $S$. ratti ESTs have been used to construct microarrays, which have been used for expression analysis of the free-living and parasitic stages. ${ }^{100}$ Transcriptome analysis of L3 stage larvae of $S$. stercoralis revealed that $42.25 \%(3,412$ ESTs) of putative proteins had homology with $C$. elegans, $47.96 \%$ had homology with $S$. ratti transcriptome, and 3,759 putative proteins were similar to human. ${ }^{102}$ Polyadenylated transcriptome analysis of $S$. stercoralis and comparison with dauer stage $C$. elegans revealed that in both $S$. stercoralis and C. elegans, the genes encoding Cyclic Guanosine Monophosphate (cGMP) pathway components were coordinately upregulated in L3i, suggesting that dauer pathway genes are present in S. stercoralis and may play a role in L3i development. ${ }^{103}$ Microarray analysis of L3i and L1 of S. stercoralis helped to identify 935 differentially expressed genes between these two stages, ${ }^{104}$ and similar results were reported using $S$. ratti transcriptome. ${ }^{100}$ Overall, using Strongyloides EST representation and microarray data, there was rather little evidence for the conservation of transcriptional profiles between $S$. ratti and $S$. stercoralis or C. elegans. ${ }^{100}$

The Wellcome Trust Sanger Institute is now in the process of sequencing the $S$. ratti genome (together with four other helminth species) as a reference genome, with subsequent whole genome shotgun sequencing of the S. stercoralis genome planned (http://www.sanger.ac.uk/ Projects/Helminths/). This gene discovery will facilitate research on these species. However, in view of the substantial diversity among the nematodes and the relative lack of tools for investigating gene function in parasitic species, a very substantial amount of work remains to be done.

Proteomic analysis of excretory/secretory proteins in $S$. ratti revealed specific expressions of 196, 79, and 35 proteins in infective larvae, parasitic female, and freeliving stages, respectively. The study identified homologs of NIE and metalloprotease astacin expressed in the infective stage. ${ }^{105}$ A systematic study identified batteries of $S$. stercoralis L3 surface antigens and somatic antigens by proteomic analysis. ${ }^{106}$ These stage-specific proteins are crucial for host-parasite interactions. However, much remains to be done as it is very challenging to obtain pure parasite proteins.

\section{Conclusion}

$S$. stercoralis is the only nematode parasite that completes its entire life cycle within the host and survives for a long time or throughout the lifetime with/without mild gastrointestinal symptoms. In majority of people, it succeeds many decades of survival by evading the host immune system. These hosts serve as reservoirs to infect people in close contacts with toiletries or contaminating soil to infect other primates. The advantage for $S$. stercoralis is its simplest life cycles, involving two alternative life cycles according to their environment: 1) capable of free-living sexual life cycle and 2) parasitic asexual life cycle. Thus, this parasite exhibits a global distribution emerging even in developed countries where there is rare fecal contamination. A balance between parasite and host immune system, which is affected due to HTLV-1 viral infection or corticosteroid therapies for asthma, tissue transplantation, and cancer treatment, allows parasite multiplication that leads to disseminated strongyloidiasis. Majority of the fatal disease is attributable to the invasion of parasite to all organs in the body. It is important to screen Strongyloides 
infections before tissue transplantation, cancer therapies, or corticosteroid therapies. Health care providers should be educated and should consider patients' origin and travel history to endemic countries to recognize the possibility of this neglected parasitic infection. Recently a diagnostic assay developed based on a recombinant NIE antigen has been shown to be specific and sensitive to $S$. stercoralis infection and can be used for prescreening and estimating the global prevalence of the parasite. Early diagnosis of strongyloidiasis and use of ivermectin for treatment (a drug of choice that avoids various clinical complications and other unnecessary invasive diagnostic procedures) are vital in containment of the disease, whereas genomic and proteomic advances will unravel the understanding of biology of the parasite and aid in the development of an efficacious vaccine.

\section{Disclosure}

The authors report no conflicts of interest in this work.

\section{References}

1. Olsen A, van Lieshout L, Marti H, et al. Strongyloidiasis - the most neglected of the neglected tropical diseases? Trans $R$ Soc Trop Med Hyg. 2009;103:967-972.

2. Ashford RW, Barnish G, Viney ME. Strongyloides fuelleborni kellyi: infection and disease in Papua New Guinea. Parasitol Today. 1992; 8(9):314-318.

3. Abrescia FF, Falda A, Caramaschi G, et al. Reemergence of strongyloidiasis, Northern Italy. Emerg Infect Dis. 2009;15:1531-1533.

4. Adams M, Page W, Speare R. Strongyloidiasis: an issue in aboriginal communities. Rural Remote Health. 2003;3(1):152.

5. Carvalho M, Porto DF. Epidemiological and clinical interaction between HTLV-1 and Strongyloides stercoralis. Parasite Immunol. 2004;26:487-497.

6. Toledo R, Muñoz-Antoli C, Esteban JG. Strongyloidiasis with emphasis on human infections and its different clinical forms. Adv Parasitol. 2015;88:165-241.

7. Schär F, Trostdorf U, Giardina F. Strongyloides stercoralis: global distribution and risk factors. PLoS Negl Trop Dis. 2013;7(7):e2288.

8. Roberts AL, Schneider AE, Young RL, Hinrichs SH, Iwen PC. Strongyloides stercoralis infection in a non-endemic area. Lab Medicine. 2013;44:339-343.

9. Uparanukraw P, Phongsri S, Morakote N. Fluctuation of larval excretion in Strongyloides stercoralis infection. Am J Med Hyg. 1999;60:967-973.

10. Scowden EB, Schaffner W, Stone WJ. Overwhelming strongyloidiasis: an unappreciated opportunistic infection. Medicine (Baltimore). 1978;57(6):527-544

11. Burke JA. Strongyloidiasis in childhood. Am J Dis Child. 1978;132: 1130-1136.

12. Kukuruzovic R, Robins-Browne RM, Anstey NM, Brewster DR. Enteric pathogens, intestinal permeability and nitric oxide production in acute gastroenteritis. Paediatr Infect Dis J. 2002;21:730-739.

13. Fisher D, McCarry F, Currie B. Strongyloidiasis in the Northern Territory. 'Under-recognised and under-treated?'. Med J Aust. 1993;159:88-90.

14. Dawson-Hahn EE, Greenberg SL, Domachowske JB, Olson BG. Eosinophilia and the seroprevalence of schistosomiasis and strongyloidiasis in newly arrived pediatric refugees: an examination of Centers for Disease Control and Prevention Screening Guidelines. J Pediatr. 2010;156:1016-1018.
15. Prociv P, Luke R. Observations on strongyloidiasis in Queensland aboriginal communities. Med J Aust. 1993;158:160-163.

16. Neumann I, Ritter R, Mounsey A. Strongyloides as a cause of fever of unknown origin. J Am Board Fam Med. 2012;25(3):390-393.

17. Nwokolo C, Imobiosen EAE. Strongyloidiasis of respiratory tract presenting as asthma. Br Med J. 1973;2:153-154.

18. Woodring JH, Halfhill H 2nd, Reed JC. Pulmonary strongyloidiasis: clinical and imaging features. AJR Am J Roentgenol. 1994;162(3): $537-542$.

19. Keiser PB, Nutman TB. Strongyloides stercoralis in the immunocompromised population. Clin Microbiol Rev. 2004;17(1):208-217.

20. Sharifdini M, Kia EB, Ashrafi K, et al. An analysis of clinical characteristics of Strongyloides stercoralis in 70 indigenous patients in Iran. Iran J Parasitol. 2014;9(2):155-162.

21. Chu E, Whitlock WL, Dietrich RA. Pulmonary hyperinfection syndrome with Strongyloides stercoralis. Chest. 1990;97:1475-1477.

22. Lin AL, Kessimian N, Benditt JO. Restrictive pulmonary disease due to interlobular septal fibrosis associated with disseminated infection by Strongyloides stercoralis. Am J Respir Crit Care Med. 1995;151(1):205-209.

23. Mukerjee CM, Carrick J, Walker JC, Woods RL. Pulmonary strongyloidiasis presenting as chronic bronchitis leading to interlobular septal fibrosis and cured by treatment. Respirology. 2003;8(4):536-540.

24. Jayaprakash B, Sandhya S, Anithakumari K. Pulmonary strongyloidiasis. JAssoc Physicians India. 2009;57:535-536.

25. Agarwala R, Wasielewski J, Biman B. Pulmonary strongyloidiasis following renal transplantation without travel to an endemic area. Oxf Med Case Reports. 2014;15(4):83-85.

26. Bruno P, McAllister K, Matthews JI. Pulmonary strongyloidiasis. South Med J. 1982;75:363-365.

27. Yee A, Boylen CT, Noguchi T, Klatt EC, Sharma OP. Fatal Strongyloides stercoralis infection in a patient receiving corticosteroids. West J Med. 1987;146:363-364.

28. Cahill KM, Shevchuk M. Fulminant, systemic strongyloidiasis in AIDS. Ann Trop Med Parasitol. 1996;90:313-318.

29. Nomura J, Rekrut K. Strongyloides stercoralis hyperinfection syndrome in a patient with AIDS: diagnosis by fluorescent microscopy. Clin Infect Dis. 1996;22(4):736.

30. Ravi V, Ramachandran S, Thompson RW, Andersen JF, Neva FA. Characterization of a recombinant immunodiagnostic antigen (NIE) from Strongyloides stercoralis L3-stage larvae. Mol Biochem Parasitol. 2002;125(1-2):73-81.

31. Pillai KR, Nair GR, Amma NS, Nair MK. Diagnosis of pulmonary strongyloidiasis by sputum cytology: a case report. Indian J Pathol Microbiol. 1993;36(4):489-491.

32. Lessnau KD, Can S, Talavera W. Disseminated Strongyloides stercoralis in human immunodeficiency virus-infected patients. Treatment failure and a review of the literature. Chest. 1993;104:119-122.

33. Celedon JC, Mathur-Wagh U, Fox J, Garcia R, Wiest PM. Systemic strongyloidiasis in patients infected with the human immunodeficiency virus. A report of 3 cases and review of the literature. Medicine (Baltimore). 1994;73:256-263.

34. Conlon CP, Pinching AJ, Perera CU, Moody A, Luo NP, Lucas SB. HIV related enteropathy in Zambia: a clinical, microbiological and histological study. Am J Trop Med Hyg. 1990;42:83-88.

35. Vinay ME, Brown M, Omoding NE, et al. Why does HIV infection not lead to disseminated strongyloidiasis? J Infect Dis. 2004;190: 2175-2180.

36. Hayashi J, Kishihara Y, Yoshimura E, et al. Correlation between human T cell lymphotropic virus type-1 and Strongyloides stercoralis infections and serum immunoglobulin E response in residents of Okinawa, Japan. Am J Trop Med Hyg. 1997;56:71-75.

37. Hirata T, Uchima N, Kishimoto K, et al. Impairment of host immune response against Strongyloides stercoralis by human T cell lymphotropic virus type I infection. Am J Trop Med Hyg. 2006;74:246-249.

38. Nakada K, Yamaguchi K, Furugen S, et al. Monoclonal integration of HTLV-I proviral DNA in patients with strongyloidiasis. Int $J$ Cancer. 1987;40(2):145-148. 
39. Satoh M, Toma $\mathrm{H}$, Sugahara $\mathrm{K}$, et al. Involvement of IL-2/IL-2R system activation by parasite antigen in polyclonal expansion of CD4+25+ HTLV-1 infected T-cells in human carrier of both HTLV-1 and S. stercoralis. Oncogene. 2002;21:2466-2475.

40. Adedayo O, Grell G, Bellot P. Hyperinfective strongyloidiasis in the medical ward: a review of 27 cases in 5 years. South Med J. 2002;95:711-716

41. Patey O, Gessain A, Breuil J, et al. Seven years of recurrent strongyloidiasis in an HTLV-1 infected man who developed adult T-cell leukaemia. AIDS. 1992;6:575-579.

42. Adedayo AO, Grell GA, Bellot P. Case study: fatal strongyloidiasis associated with human T-cell lymphotropic virus type 1 infection. Am J Trop Med Hyg. 2001;65(5):650-651.

43. Satoh M, Toma H, Sato Y, et al. Reduced efficacy of treatment of strongyloidiasis in HTLV-1 carriers related to enhanced expression of IFN-g and TGF b1. Clin Exp Immunol. 2002;127:354-359.

44. Zaha O, Hirata T, Uchima N, Kinjo F, Saito A. Comparison of anthelmintic effects of two doses of ivermectin on intestinal strongyloidiasis in patients negative or positive for anti-HTLV-1 antibody. $J$ Infect Chemother. 2004;10:348-351.

45. Newton RC, Limpuangthip P, Greenberg S, Gam A, Neva FA. Strongyloides stercoralis hyper infection in a carrier of HTLV-1 virus with evidence of selective immunosuppression. Am J Med. 1992;92: 202-208.

46. Montes M, Sanchez C, Verdonck K, et al. Regulatory T Cell expansion in HTLV-1 and strongyloidiasis coinfection is associated with reduced IL-5 responses to Strongyloides stercoralis antigen. PLoS Negl Trop Dis. 2009;3:e456.

47. Klion AD, Nutman TB. The role of eosinophils in the host defense against helminth parasites. J Allergy Clin Immunol. 2004;113:30-37.

48. Steinmann P, Zhou XN, Du ZW, et al. Tribendimidine and albendazole for treating soil-transmitted helminths, Strongyloides stercoralis and Taenia spp.: open-label randomized trial. PLoS Negl Trop Dis. 2008;2(10):e322.

49. Gann PH, Neva FA, Gam AA. A randomized trial of single and twodose ivermectin versus thiabendazole for treatment of strongyloidiasis. J Infect Dis. 1994;169:1076-1079.

50. Igual-Adell R, Oltra-Alcaraz C, Soler-Company E, Sánchez-Sánchez P, Matogo-Oyana J, Rodríguez-Calabuig D. Efficacy and safety of ivermectin and thiabendazole in the treatment of strongyloidiasis. Expert Opin Pharmacother. 2004;5:2615-2619.

51. Marti H, Haji HJ, Savioli L, et al. A comparative trial of a single dose ivermectin versus three days of albendazole for treatment of Strongyloides stercoralis and other soil-transmitted helminth infections in children. Am J Trop Med Hyg. 1996;55:477-481.

52. Daubenton JD, Buys HA, Hartley PS. Disseminated strongyloidiasis in a child with lymphoblastic lymphoma. J Pediatr Hemato Oncol. 1998;20:260-263.

53. Cruz T, Reboucas G, Rocha H. Fatal strongyloidiasis in patients receiving corticosteroid. N Engl J Med. 1996;275:1093-1096.

54. Satoh M, Toma H, Sato Y, et al. Production of a high level of specific IgG4 antibody associated with resistance to albendazole treatment in HLA-DRB1*0901-positive patients with strongyloidiasis. Am J Trop Med Hyg. 1999;61(4):668-671.

55. Lanafame M, Faggian F, Lattuada E, Antolini D, Vento S. Strongyloidiasis in an HIV-1 infected patient after highly active antiretroviral therapy-induced immune restoration. J Infect Dis. 2005;191(6):1027.

56. Brown M, Cartledge JD, Miller RF. Dissemination of Strongyloides stercoralis as an immune restoration phenomenon in an HIV-1 infected man on antiretroviral therapy. Int J STD AIDS. 2006;17:560-561.

57. Torres JR, Isturiz R, Murillo J, Guzman M, Contreras R. Efficacy of ivermectin in the treatment of strongyloidiasis complicating AIDS. Clin Infect Dis. 1993;17:900-902.

58. WHO. Bench Aids for the Diagnosis of Intestinal Parasites. Geneva: WHO; 1994.

59. de Kaminsky RG. Evaluation of three methods for laboratory diagnosis of Strongyloides stercoralis infection. J Parasitol. 1993;79:277-280.
60. Sato Y, Kobayashi J, Toma H, Shiroma Y. Efficacy of stool examination for detection of Strongyloides infection. Am J Trop Med Hyg. 1995;53(3):248-250.

61. ten Hove RJ, Verweij JJ, Vereecken K, Polman K, Dieye L, van Lieshout L. Multiplex real-time PCR for the detection and quantification of Schistosoma mansoni and S. haematobium infection in stool samples collected in northern Senegal. Trans R Soc Trop Med Hyg. 2008;102:179-185.

62. Hasegawa H, Hayashida S, Ikeda Y, Sato H. Hyper-variable regions in 18S rDNA of Strongyloides spp. as markers for species-specific diagnosis. Parasitol Res. 2009;104:869-874.

63. Moghaddassani H, Mirhendi H, Hosseini M, Rokni M, Mowlavi G, Kia E. Molecular diagnosis of Strongyloides stercoralis infection by PCR detection of specific DNA in human stool samples. Iran J Parasitol. 2011;6(2):23-30.

64. Mejia R, Vicuña Y, Broncano N, et al. A novel, multi-parallel, real-time polymerase chain reaction approach for eight gastrointestinal parasites provides improved diagnostic capabilities to resource-limited at-risk populations. Am J Trop Med Hyg. 2013;88(6):1041-1047.

65. Sharifdini M, Mirhendi H, Ashrafi K, et al. Comparison of nested polymerase chain reaction and real time polymerase chain reaction with parasitological methods for detection of Strongyloides stercoralis in human fecal samples. Am J Trop Med Hyg. 2015;93(6):1285-1291.

66. Saugar JM, Merino FJ, Martín-Rabadán P, et al. Application of realtime PCR for the detection of Strongyloides spp. in clinical samples in a reference center in Spain. Acta Trop. 2015;142:20-25.

67. Verweij JJ, Canales M, Polman K, et al. Molecular diagnosis of Strongyloides stercoralis in faecal samples using real-time PCR. Trans $R$ Soc Trop Med Hyg. 2009;103:342-346.

68. Brindley PJ, Gam AA, Pearce EJ, Poindexter RW, Neva FA. Antigens from the surface and excretions/secretions of the filariform larva of Strongyloides stercoralis. Mol Biochem Parasitol. 1988;28(3): 171-180.

69. Conway DJ, Bailey JW, Lindo JF, Robinson RD, Bundy DA, Bianco AE. Serum IgG reactivity with 41-, 31-, and 28-kDa larval proteins of Strongyloides stercoralis in individuals with strongyloidiasis. $J$ Infect Dis. 1993;168:784-787.

70. Conway DJ, Lindo JF, Robinson RD, Bundy DA, Bianco AE. Strongyloides stercoralis: characterization of immunodiagnostic larval antigens. Exp Parasitol. 1994;79:99-105.

71. Genta RM. Predictive value of an enzyme-linked immunosorbent assay (ELISA) for the serodiagnosis of strongyloidiasis. Am J Clin Pathol. 1988;89(3):391-394.

72. Bailey JW. A serological test for the diagnosis of Strongyloides antibodies in ex Far East Prisoners of War. Ann Trop Med Parasitol. 1989;83(3):241-247.

73. Mangali A, Chaicumpa W, Nontasut P, Chantavanij P, Tapchaisri P, Viravan C. Enzyme-linked immunosorbent assay for diagnosis of human strongyloidiasis. Southeast Asian J Trop Med Public Health. 1991;22(1):88-92.

74. van Doorn HR, Koelewijn R, Hofwegen H, et al. Use of enzyme-linked immunosorbent assay and dipstick assay for detection of Strongyloides stercoralis infection in humans. J Clin Microbiol. 2007;45:438-442.

75. Gam AA, Neva FA, Krotoski WA. Comparative sensitivity and specificity of ELISA and IHA for serodiagnosis of strongyloidiasis with larval antigens. Am J Trop Med Hyg. 1987;37:157-161.

76. Ramachandran S, Thompson RW, Gam AA, Neva FA. Recombinant cDNA clones for immunodiagnosis of strongyloidiasis. $J$ Infect Dis. 1998;177:196-203.

77. Brodine SK, Thomas A, Huang R, et al. Community based parasitic screening and treatment of Sudanese refugees: application and assessment of Centers for Disease Control guidelines. Am J Trop Med Hyg. 2009;80(3):425-430.

78. Ramanathan R, Burbelo PD, Groot S, Iadarola MJ, Neva FA, Nutman TB. A luciferase immunoprecipitation systems assay enhances the sensitivity and specificity of diagnosis of Strongyloides stercoralis infection. J Infect Dis. 2008;198(3):444-451. 
79. Satoh M, Kokaze A. Treatment strategies in controlling strongyloidiasis. Expert Opin Pharmacother. 2004;5:2293-2301.

80. Lim S, Katz K, Krajden S, Fuksa M, Keystone JS, Kain KC. Complicated and fatal Strongyloides infection in Canadians: risk factors, diagnosis and management. CMAJ. 2004;171:479-484.

81. Plata-Menchaca EP, de Leon VM, Peña-Romero AG, Rivero-Sigarroa E. Pulmonary hemorrhage secondary to disseminated strongyloidiasis in a patient with systemic lupus erythematosus. Case Rep Crit Care. 2015;2015:310185.

82. Goka AK, Rolston DD, Mathan VI, Farthing MJ. Diagnosis of Strongyloides and hookworm infections: comparison of fecal and duodenal fluid microscopy. Trans R Soc Trop Med Hyg. 1990;84:829-831.

83. Heyworth MF. Parasitic diseases in immunocompromised hosts. Cryptosporidiosis, isosporiasis, and strongyloidiasis. Gastroenterol Clin North Am. 1996;25:691-707.

84. Genta RM. Strongyloides stercoralis. In: Blaser MJ, Smith PD, Ravdin JI, Greenberg HB, Guerrant RL, editors. Infections of the Gastrointestinal Tract. New York, NY: Raven Press; 1995:1197-1207.

85. Herbert DR, Nolan TJ, Schad GA. Immunoaffinity-isolated antigens induce protective immunity against larval Strongyloides stercoralis in mice. Exp Parasitol. 2002;100(2):112-120.

86. Abraham D, Hess JA, Mejia R. Immunization with the recombinant antigen Ss-IR induces protective immunity to infection with Strongyloides stercoralis in mice. Vaccine. 2011;29:8134-8140.

87. Kerepesi LA, Keiser PB, Nolan TJ. DNA immunization with Na+-K+ ATPase (Sseat-6) induces protective immunity to larval Strongyloides stercoralis in mice. Infect Immun. 2005;73:2298-2305.

88. Ligas JA, Kerepesi LA, Galioto AM, et al. Specificity and mechanism of immunoglobulin M (IgM)- and IgG-dependent protective immunity to larval Strongyloides stercoralis in mice. Infect Immun. 2003;71:6835-6843.

89. Abraham D, Rotman HL, Haberstroh HF, et al. Strongyloides stercoralis: protective immunity to third-stage larvae inBALB/cByJ mice. Exp Parasitol. 1995;80:297-307.

90. Nouir NB, Eschbach ML, Piédavent M, et al. Vaccination with Strongyloides ratti heat shock protein 60 increases susceptibility to challenge infection by induction of Th1 response. Vaccine. 2012;30(5):862-871

91. Nouir NB, Piédavent M, Osterloh A, Breloer M. Passive immunization with a monoclonal IgM antibody specific for Strongyloides ratti HSP60 protects mice against challenge infection. Vaccine. 2012;30(33):4971-4976.

92. Vlaminck J, López-Abán J, Ruano AL, del Olmo E, Muro A. Vaccination against Strongyloides venezuelensis with homologue antigens using new immunomodulators. J Parasitol. 2010;96(3):643-647.
93. Streit A. How to become a parasite without sex chromosomes: a hypothesis for the evolution of Strongyloides spp. and related nematodes. Parasitology. 2014;141(10):1244-1254.

94. Blaxter ML, De Ley P, Garey JR, et al. A molecular evolutionary framework for the phylum Nematoda. Nature. 1998;392(6671):71-75.

95. Lok JB. Strongyloides stercoralis and relatives: recent advances in general and molecular biology. Curr Trop Med Rep. 2014;1:194-206.

96. Thompson FJ, Mitreva M, Barker GL, et al. An expressed sequence tag analysis of the life-cycle of the parasitic nematode Strongyloides ratti. Mol Biochem Parasitol. 2005;142(1):32-46.

97. Viney ME. The biology and genomics of Strongyloides. Med Microbiol Immunol. 2006;195(2):49-54.

98. Mitreva M, McCarter JP, Martin J, et al. Comparative genomics of gene expression in the parasitic and free-living nematodes Strongyloides stercoralis and Caenorhabditis elegans. Genome Res. 2004; 14(2):209-220.

99. Parkinson J, Mitreva M, Whitton C, et al. A transcriptomic analysis of the phylum Nematoda. Nat Genet. 2004;36(12):1259-1267.

100. Thompson FJ, Barker GL, Hughes L, Wilkes CP, Coghill J, Viney ME. A microarray analysis of gene expression in the free-living stages of the parasitic nematode Strongyloides ratti. BMC Genomics. 2006;7:157.

101. Hu M, Chilton NB, Gasser RB. The mitochondrial genome of Strongyloides stercoralis (Nematoda)- idiosyncratic gene order and evolutionary implications. Inl J Parasitol. 2003;33(12):1393-1408.

102. Marcilla A, Garg G, Bernal D, et al. The transcriptome analysis of Strongyloides stercoralis L3i larvae reveals targets for intervention in a neglected disease. PLoS Negl Trop Dis. 2012;6(2):e1513.

103. Stoltzfus JD, Minot S, Berriman M, Nolan TJ, Lok JB. RNAseq analysis of the parasitic nematode Strongyloides stercoralis reveals divergent regulation of canonical dauer pathways. PLoS Negl Trop Dis. 2012;6(10):e1854.

104. Ramanathan R, Varma S, Ribeiro JM, et al. Microarray-based analysis of differential gene expression between infective and noninfective larvae of Strongyloides stercoralis. PLoS Negl Trop Dis. 2011;5(5):e1039.

105. Soblik H, Younis AE, Mitreva M, et al. Life cycle stage-resolved proteomic analysis of the excretome/secretome from Strongyloides ratti-identification of stage-specific proteases. Mol Cell Proteomics. 2011;10(12):M111.010157.

106. Marcilla A, Sotillo J, Perez-Garcia A, et al. Proteomic analysis of Strongyloides stercoralis L3 larvae. Parasitology. 2010;137: 1577-1583.
Reports in Parasitology

\section{Publish your work in this journal}

Reports in Parasitology is international, peer-reviewed, open access journal publishing original research, reports, reviews and commentaries on all areas of parasitology. The manuscript management system is completely online and includes a very quick and fair peer-review

\section{Dovepress}

system. Visit http://www.dovepress.com/testimonials.php to read real quotes from published authors. 